\title{
Fitotoxicidade Causada por Herbicidas na Fase Inicial de Desenvolvimento da Cultura do Sorgo ${ }^{1}$
}

\author{
Phytotoxicity Caused by Herbicides to Sorghum Crop at Early Stages of Development
}

\author{
MAGALHÃES, P.C. ${ }^{2}$, SILVA, J.B. ${ }^{3}$, DURÃES, F.O.M. ${ }^{2}$ e RIBEIRO, L.S. ${ }^{4}$
}

\begin{abstract}
RESUMO - A utilização de herbicidas em pós-emergência inicial ou tardia em jato dirigido à cultura de sorgo cresceu muito com o aumento da área plantada da cultura. No entanto, estes herbicidas podem causar injúrias às plantas de sorgo, quando não são totalmente seletivos. Como esses herbicidas são basicamente bloqueadores de processos metabólicos, surge a dúvida sobre quais serão os efeitos dessas injúrias na produção final de grãos de sorgo. Assim, o objetivo deste trabalho foi estudar o efeito da toxicidade à cultura causada pela aplicação de herbicidas na fase inicial e em pós-emergência tardia em jato dirigido e o seu efeito na produção de grãos. Este estudo foi conduzido durante os anos agrícolas 1994/95 e 1995/96, utilizandose o híbrido BR 700, no delineamento experimental de blocos ao acaso, com 12 tratamentos e quatro repetições. Os tratamentos consistiram da aplicação da combinação dos seguintes herbicidas em diferentes doses: cyanazine + simazine com e sem óleo mineral, aplicados nos estádios de crescimentos de 4 e 6 folhas, e paraquat + espalhante adesivo e ametryn + óleo mineral , aplicados em jato dirigido no estádio de 12 folhas. Foram incluídas também testemunhas com e sem capina, além da retirada mecânica das folhas do 1, 2으 e 3ํ pares de folhas. Foram avaliados área foliar, peso da matéria seca da parte aérea, teor de clorofila nas folhas, altura da planta, diâmetro do colmo, estande, peso de 1.000 grãos, peso de panículas e produção de grãos. A aplicação de cyanazine + simazine + óleo mineral, no estádio de 4 folhas, reduziu drasticamente o estande das plantas de sorgo, nos dois períodos avaliados. O desenvolvimento das plantas, medido pela área foliar e pelo diâmetro do caule, foi pouco afetado, sendo os piores desempenhos verificados na testemunha sem capina e com a aplicação da mistura cyanazine + simazine. A redução no estande afetou diretamente a produção de panículas e de grãos. Os tratamentos que proporcionaram os mais altos rendimentos foram: paraquat + espalhante adesivo, ametryn + óleo mineral, retirada mecânica de folhas e cyanazine + simazine aplicados no estádio de 6 folhas. À exceção do tratamento cyanazine + simazine aplicado no estádio de 4 folhas, o uso de herbicidas em pós-emergência inicial e área total na cultura do sorgo mostrou-se seletiva . Mesmo quando houve injúrias, decorrentes da ação dos herbicidas, elas não foram suficientes para prejudicar a produção. O bom controle das plantas daninhas proveniente do uso dos herbicidas possibilitou ao sorgo expressar melhor seu potencial produtivo.
\end{abstract}

Palavras-chave: pós-emergência, jato dirigido, Sorghum bicolor.

ABSTRACT - The application of herbicides in early broadcast postemergence and band directed of herbicides in sorghum has raised considerably with increasing planting acreage in Brazil. However, these products can cause phytoxicity since they are not completely selective to the crop. Since these herbicides basically block metabolic processes in the plants, one questions what effects these injuries will have on grain yield. Therefore, the objective of this research was to study the phytotoxic effect caused by the application of herbicides on the crop, at the initial phase and at late postemergence in directed spray, as well as on sorghum grain yield. This study was carried out during the growing season of 1994/95 and 1995/96, using the hybrid $B R 700$, in a complete randomized block design, with 12 treatments and four replications. The treatments consisted of the combination of the following herbicides at several rates: cyanazine + simazine with or without mineral oil, applied at the 4-and-6 leaf growth stages; paraquat +

Recebido para publicação em 30/11/1999 e na forma revisada em 15/3/2000.

2 Pesquisadores, Ph.D., Embrapa Milho e Sorgo, Sete Lagoas-MG. ${ }^{3}$ Consultor Autônomo, Ph.D., Sete Lagoas-MG. ${ }^{4}$ Eng.$\mathrm{Agr}^{\circ}$., B.Sc, estagiária da Embrapa Milho e Sorgo. 
adjuvant and ametryn + mineral oil, applied as directed spray at the 12-leaf growth stage. The control treatments were weed free and weeded plus mechanical defoliation of the first, second and third pair of sorghum leaves at the 12-leaf stage. Leaf area, plant dry weight, leaf chlorophyll content, plant height, stand, weight of panicles and grain yield were also evaluated. Cyanazine + simazine + mineral oil application at the 4-leaf growth stage drastically reduced sorghum stand in both evaluations. Plant development evaluated by leaf area and stem diameter was not much affected. The poorest performances were observed with the weeded treatment and cyanazine + simazine. Stand reduction affected the panicles and grain yield directly. The best treatments for weed control were: paraquat + adjuvant, ametryn + mineral oil, mechanical defoliation and cyanazine + simazine applied at the 6-leaf growth stage. Except for the application of cyanazine + simazine at the 4-leaf growth stage, herbicide application in postemergence on sorghum crop was selective. Even though injuries were caused by the herbicides, they did not cause a reduction in the sorghum grain yield. Good weed control using herbicides allowed the sorghum plants to better express their yield potential.

Key words: postemergence, direct spray, Sorghum bicolor.

\section{INTRODUÇÃO}

Atualmente, o sorgo ocupa, entre os cereais, o quinto lugar em área plantada no mundo, atrás de trigo, arroz, milho e cevada. A produção de sorgo na América do Norte, América do Sul, Europa e Austrália se destina principalmente à alimentação animal, ao passo que na Ásia, África, Rússia, China e América Central o grão é importante como alimento humano básico (Paul, 1990). O aumento da área plantada de sorgo, no Brasil, tem demandado o uso de novas tecnologias, dentre as quais a aplicação de herbicidas em pós-emergência tem merecido destaque (Sorgo, 1998). A planta de sorgo tolera mais o déficit de água e o excesso de umidade no solo do que a maioria dos cereais e pode ser cultivada numa ampla faixa de condições de solo (Doggett, 1970). No entanto, nos estádios iniciais de desenvolvimento, as plantas de sorgo são relativamente pequenas, frágeis e de crescimento lento (Kramer \& Ross 1975). A competição com plantas daninhas nessa fase é bastante crítica, e, se medidas de controle não forem tomadas nas primeiras semanas após a emergência das plantas de sorgo, a produção de grãos pode ser reduzida em torno de 35\% (Silva et al., 1998). Deve-se considerar, entretanto, que herbicidas não totalmente seletivos podem causar injúrias às plantas de sorgo, quando estas são involuntariamente atingidas. Como esses agentes químicos são basicamente bloqueadores de processos metabólicos, entre os quais a fotossíntese, a grande questão que surge é: quais serão os efeitos dessas injúrias no processo produtivo da cultura? Durante o ciclo, a planta de sorgo depende das folhas, como os principais órgãos fotossintéticos, e a taxa de crescimento da planta depende tanto da taxa de expansão da área foliar como da taxa de fotossintese por unidade de área foliar (Paul, 1990).

Resultados preliminares têm mostrado que o sorgo tem respondido positivamente à aplicação de herbicidas em pós-emergência, com produção de grãos bem acima do tratamento controle. No entanto, a época de aplicação e o tipo de herbicida selecionado são decisivos na obtenção de um bom resultado (Magalhães et al., 1999).

Não existem hoje dados suficientes na literatura para responder questionamentos relativos a uma possivel queda na produção de grãos quando as plantas de sorgo são atingidas por herbicidas não totalmente seletivos. Nesse contexto, o objetivo deste trabalho foi avaliar o efeito da toxicidade causada pela aplicação dos herbicidas em pós-emergência inicial e tardia da cultura e o seu efeito na produção de grãos.

\section{MATERIAL E MÉTODOS}

O ensaio foi conduzido na área experimental da Embrapa Milho e Sorgo, Sete LagoasMG, durante os anos agrícolas 1994/95 e 1995/96. O solo utilizado foi um Latossolo Vermelho-Escuro, fase cerrado, textura argilosa, adubado de acordo com a recomendação da análise do solo. Para o ano agrícola 1994/ 95 foram aplicados no plantio $350 \mathrm{~kg} \mathrm{ha}^{-1} \mathrm{da}$ fórmula 4-30-16 + zinco e $45 \mathrm{~kg} \mathrm{ha}^{-1} \mathrm{de} \mathrm{N}$ em cobertura; no ano seguinte foram usados 
$400 \mathrm{~kg} \mathrm{ha}^{-1} \mathrm{da}$ fórmula 4-14-8 + zinco e $45 \mathrm{~kg} \mathrm{ha}^{-1}$ de $\mathrm{N}$ em cobertura. A área experimental foi irrigada sempre que necessário, baseando-se em leituras de tensiômetros instalados previamente a 20 e $40 \mathrm{~cm}$ de profundidade. Adotou-se o limite de -0,07 MPa como o momento da irrigação. Foi utilizado o cultivar de sorgo BR 700, híbrido de duplo propósito, para avaliar os seguintes tratamentos:

1. Cyanazine + Simazine + Assist (pósemergência, no estádio de 4 folhas).

2. Cyanazine + Simazine (pós-emergência, no estádio de 4 folhas).

3. Cyanazine + Simazine + Assist (pósemergência, no estádio de 6 folhas).

4. Cyanazine + Simazine (pós-emergência, no estádio de 6 folhas).

5. Paraquat + Extravon (jato dirigido ao $1^{\circ}$ par de folhas, no estádio de 12 folhas).

6. Paraquat + Extravon (jato dirigido ao 3o par de folhas, no estádio de 12 folhas).

7. Ametryn + Assist (jato dirigido ao $1^{\circ}$ par de folhas, no estádio de 12 folhas).

8. Ametryn + Assist (jato dirigido ao $3 \circ$ par de folhas, no estádio de 12 folhas).

9. Retirada manual do $1^{\circ}$ par de folhas (no estádio de 12 folhas).

10. Retirada manual do $1^{\circ}$ ao $3^{\circ}$ par de folhas (no estádio de 12 folhas).

11. Testemunha com capina.

12. Testemunha sem capina.

As doses e os produtos comerciais utilizados no ensaio foram: Blazina SC (cyanazine + simazine) a 6,4 $\mathrm{L} \mathrm{ha}^{-1}$; Gramoxone 200 (paraquat) a $2 \mathrm{~L} \mathrm{ha}^{-1}$; Gesapax (ametryn) a $2,5 \mathrm{~L} \mathrm{ha}^{-1}$; Assist a $0,5 \% \mathrm{v} / \mathrm{v}$; e Extravon a $0,1 \% \mathrm{v} / \mathrm{v}$.

A aplicação dos tratamentos foi estabelecida em diferentes estádios de desenvolvimento da cultura, quando as plantas apresentavam 4, 6 e 12 folhas completamente desenvolvidas (Ritchie e Hanway, 1989). A pulverização nos estádios iniciais foi realizada em área total, utilizando-se um pulverizador tipo monociclo equipado com barra de oito bicos APJ-110.R, pressão de $2,75 \mathrm{kgf} \mathrm{cm}^{-2}$, com uma vazão de $240 \mathrm{~L} \mathrm{ha}^{-1}$. A pressão de pulverização foi obtida por meio de um cilindro de $\mathrm{CO}_{2}$ e controlada por um manômetro de baixa pressão. As condições climáticas para o ano agrícola 1994/
95, no período da aplicação (estádios de 4 e 6 folhas), apresentaram-se com uma temperatura média em torno de $30,5^{\circ} \mathrm{C}$ e umidade relativa de $63 \%$. Para o ano seguinte, no mesmo período, foram registrados $29,5{ }^{\circ} \mathrm{C}$ de temperatura e umidade relativa de $68 \%$.

No estádio de 12 folhas, a pulverização foi feita no centro das entrelinhas com um pulverizador costal tipo mochila, tanque de $10 \mathrm{~L}$, pressurizado a $\mathrm{CO}_{2}$ e munido de um bico TF-VS3 (floodjet), pressão de $2,00 \mathrm{kgf} \mathrm{cm}^{-2}$, com uma vazão de $295 \mathrm{~L} \mathrm{ha}^{-1}$, ajustando-se a altura do bico para atingir o primeiro par de folhas baixeiras do sorgo (tratamentos 5 e 7) e até o terceiro par de folhas (tratamentos 6 e 8). As condições climáticas relativas a temperatura e umidade relativa para as épocas de aplicação foram, respectivamente, de $29,1{ }^{\circ} \mathrm{C}$ e $75 \%$ (ano agrícola $1994 / 95$ ) e $29,0{ }^{\circ} \mathrm{C}$ e $79 \%$ (ano agrícola $1995 /$ 96). Para evitar o efeito da interferência sobre a cultura, mascarando o efeito de injúrias químicas sobre a produtividade, todas as parcelas, com exceção das parcelas testemunhas sem capina (tratamento 12), foram capinadas manualmente, sempre que necessário. Neste trabalho, não se cogitou o efeito dos tratamentos químicos sobre as plantas daninhas, fato bastante conhecido e registrado na literatura (Silva \& Pires, 1990).

O delineamento experimental utilizado foi o de blocos ao acaso, com 12 tratamentos e quatro repetições. Na época do florescimento, foram avaliadas as seguintes características: altura da planta, área foliar, peso seco da parte aérea e teor de clorofila nas folhas; no final do ciclo da cultura avaliaram-se estande, altura da planta, diâmetro do colmo, peso de panículas, peso de 1.000 grãos e produção de grãos. A parcela experimental foi constituída de seis linhas de 7 metros de comprimento, espaçadas de $0,70 \mathrm{~m}$, com 15 sementes por metro linear; para a área útil foram consideradas as duas linhas centrais de $6 \mathrm{~m}$ de comprimento, abandonando-se 0,50 m em cada extremidade das linhas. Os dados foram submetidos à análise de variância e as médias comparadas pelo teste de Tukey. Para discussão dos resultados, nos dois anos agrícolas foram selecionados três componentes de crescimento (área foliar, diâmetro do colmo e estande) e dois componentes de produção (peso de panículas e de grãos), corrigidos para a umidade-padrão de $13 \%$. 


\section{RESULTADOS E DISCUSSÃO}

No ano agrícola 1994/95, o resultado proveniente do tratamento cyanazine + simazine + assist (4 folhas) foi suprimido das tabelas, com as características avaliadas, uma vez que o seu efeito foi devastador, causando a morte da maioria das plantas presentes na parcela experimental. A área foliar, nos dois anos agrícolas (Tabela 1), não foi influenciada pelos diversos tratamentos, apesar das diferenças numéricas verificadas. Os coeficientes de variação, sobretudo no ano agrícola 1994/95 $(46,75 \%)$, foram considerados altos (Stell \& Torrie, 1980), não sendo, portanto, possivel discriminar diferenças entre tratamentos. O diâmetro do colmo foi pouco afetado pelos tratamentos aplicados (Tabela 2).

No primeiro ano, apenas a aplicação de cyanazine + simazine ( 6 folhas) foi inferior aos tratamentos de retirada de folhas ( $1^{\circ}$ ao $3^{\circ}$ par, 12 folhas) e ametryn + assist ( $1^{\circ}$ par, 12 folhas). Os outros tratamentos se situaram em posição intermediária e não diferenciaram entre si. Já no segundo ano agrícola o menor diâmetro do caule foi obtido com o tratamento testemunha sem capina $(7,90 \mathrm{~mm})$, e o maior diâmetro $(10,10 \mathrm{~mm})$ foi obtido com a aplicação de cyanazine + simazine + assist no estádio de 4 folhas completamente desenvolvidas (Tabela 2). Não se deve ter, entretanto, a falsa impressão de que este tratamento proporcionou melhor desenvolvimento de plantas. Na verdade, a Tabela 3 mostra que o referido tratamento resultou no mais baixo estande de plantas. No ano agrícola 1994/95, esse mesmo fato foi verificado; portanto, a razão se deve provavelmente à menor competição entre plantas, que propiciou maior diâmetro do colmo destas.

O estande final de plantas (Tabela 3) foi mais afetado, no ano de 1994/95, pelos tratamentos relacionados com a aplicação de cyanazine + simazine no estádio de 4 folhas. Com a adição de assist, como já mencionado, esse tratamento causou a morte das plantas (valores não-apresentados) e, sem a adição de assist, resultou no pior estande. Está claro que a presença do óleo mineral intensificou a ação do herbicida, aumentando sua absorção foliar e causando, assim, um dano maior às plantas de sorgo (WEED...-WSSA, 1994). Interessante notar que esse mesmo tratamento aplicado no estádio de 6 folhas (sem assist) não afetou tanto o estande. No ano de 1995/96, os melhores estandes de plantas foram verificados nos tratamentos paraquat + extravon (jato no $3^{\circ}$ par, 12 folhas), ametryn + assist (jato no 3 o par, 12 folhas) e retirada de folhas ( $1^{\circ}$ ao $3^{\circ}$ par, 12 folhas). Redução de estande em sorgo tem sido relatada com o uso de graminicidas, como as cloroacetamidas ou as dinitroanilinas (Santos et al., 1998). Neste trabalho, o estande final de plantas influenciou a produção de grãos. Assim, cyanazine + simazine (4 folhas), no ano agrícola 1994/95, juntamente com testemunha sem capina, proporcionou os mais baixos rendimentos de panículas e de grãos (Tabelas 4 e 5).

Os tratamentos com maiores índices de produtividade foram paraquat + extravon (jato no $1^{\circ}$ par, 12 folhas), ametryn + assist (jato no $1^{\circ}$ par, 12 folhas), retirada de folhas ( $1^{\circ}$ ao $3^{\circ}$ par, 12 folhas), testemunha com capina e cyanazine + simazine ( 6 folhas). Os demais tratamentos situaram-se em posição intermediária. Observa-se que o tratamento de retirada de folhas do 1ํo ao 3o par, estádio de 12 folhas, foi superior a muitos tratamentos químicos, o que equivale a dizer que a perda de folhas pela planta de sorgo neste estádio não tem maiores conseqüências, mesmo porque são folhas baixeiras, de baixo índice fotossintético e já em estado de senescência.

Loomis \& Williams (1963), num estudo de estimativa do nível teórico possível de uma produção, afirmaram que cerca de $90 \%$ do peso seco das plantas consiste de produtos da fotossíntese. As folhas, portanto, são importantes como fonte supridora de fotoassimilados para cereais (Magalhães et al., 1999), porém devem estar metabolicamente ativas e protegidas de sombreamento. Enquanto o milho tem a capacidade de retranslocar fotoassimilados para os grãos em condições adversas, como perda de área foliar por necrose (Magalhães et al., 1998), o sorgo possui a capacidade de perfilhar (Stoskopf, 1985). Na ausência de estresses bióticos e abióticos, o perfilhamento pode ser considerado uma vantagem para compensação na produção, sobretudo quando há coincidência de maturação entre planta-mãe e perfilhos (Peacock \& Wilson, 1984). 
Tabela 1 - Área foliar $\left(\mathrm{cm}^{2}\right)$ de plantas de sorgo nos diferentes tratamentos estudados, nos anos agrícolas 1994/95 e 1995/96. Embrapa Milho e Sorgo, Sete Lagoas-MG

\begin{tabular}{|c|c|c|c|}
\hline \multirow{2}{*}{\multicolumn{2}{|c|}{ Tratamentos }} & \multicolumn{2}{|c|}{ Ano Agrícola } \\
\hline & & $1994 / 95$ & 1995/96 \\
\hline \multicolumn{2}{|c|}{ Retirada de folhas ( $1^{\circ}$ ao $3^{\circ}$ par, 12 folhas) } & $1.613^{1} \mathrm{a}$ & $1.887 \mathrm{a}$ \\
\hline \multicolumn{2}{|c|}{ Paraquat + Extravon (jato no $1^{\circ}$ par, 12 folhas) } & $1.520 \mathrm{a}$ & $2.400 \mathrm{a}$ \\
\hline \multicolumn{2}{|c|}{ Cyanazine + Simazine + Assist $(6$ folhas $)$} & $1.474 \mathrm{a}$ & $1.597 \mathrm{a}$ \\
\hline \multicolumn{2}{|c|}{ Ametryn + Assist (jato no $3^{\circ}$ par, 12 folhas) } & $1.322 \mathrm{a}$ & $1.840 \mathrm{a}$ \\
\hline \multicolumn{2}{|c|}{ Retirada de folhas ( $1^{\circ}$ par, 12 folhas) } & $1.320 \mathrm{a}$ & $2.175 \mathrm{a}$ \\
\hline \multicolumn{2}{|l|}{ Testemunha sem capina } & $1.320 \mathrm{a}$ & $1.593 \mathrm{a}$ \\
\hline \multicolumn{2}{|l|}{ Testemunha com capina } & $1.216 \mathrm{a}$ & $2.587 \mathrm{a}$ \\
\hline \multicolumn{2}{|c|}{ Ametryn + Assist (jato no $1^{\underline{o}}$ par, 12 folhas) } & $1.086 \mathrm{a}$ & $2.365 \mathrm{a}$ \\
\hline \multicolumn{2}{|l|}{ Cyanazine + Simazine ( 6 folhas $)$} & $1.010 \mathrm{a}$ & $1.715 \mathrm{a}$ \\
\hline \multicolumn{2}{|c|}{ Paraquat + Extravon (jato no $3^{\circ}$ par, 12 folhas) } & $900 \mathrm{a}$ & $1.914 \mathrm{a}$ \\
\hline \multicolumn{2}{|l|}{ Cyanazine + Simazine ( 4 folhas $)$} & $561 \mathrm{a}$ & $1.528 \mathrm{a}$ \\
\hline \multicolumn{2}{|c|}{ Cyanazine + Simazine + Assist $(4$ folhas $)$} & -- & $1.876 \mathrm{a}$ \\
\hline 1994/95 - Média geral $=1.210$ & $\mathrm{CV}=46,75 \%$ & Valor de $\mathrm{F}=1,17 \mathrm{~ns}$ & $\mathrm{DMS}=1.395$ \\
\hline 1995/96 - Média geral $=1.956$ & $\mathrm{CV}=24,04 \%$ & Valor de $\mathrm{F}=2,20 *$ & $\mathrm{DMS}=1.169$ \\
\hline
\end{tabular}

${ }^{1}$ Médias seguidas pela mesma letra não diferem entre si, a 5\% de probabilidade, pelo teste de Tukey.

Tabela 2 - Diâmetro médio de colmos (mm) nos diferentes tratamentos estudados, nos anos agrícolas 1994/95 e 1995/96. Embrapa Milho e Sorgo, Sete Lagoas-MG

\begin{tabular}{|c|c|c|c|}
\hline \multirow{2}{*}{\multicolumn{2}{|c|}{ Tratamentos }} & \multicolumn{2}{|c|}{ Ano Agrícola } \\
\hline & & $1994 / 95$ & $1995 / 96$ \\
\hline \multicolumn{2}{|c|}{ Retirada de folhas ( $1^{\circ}$ ao $3^{\circ}$ par, 12 folhas $)$} & $9,55^{1} \mathrm{a}$ & $9,28 \mathrm{abc}$ \\
\hline \multicolumn{2}{|c|}{ Ametryn + Assist (jato no $1^{\circ}$ par, 12 folhas) } & 9,55 a & $9,55 \mathrm{ab}$ \\
\hline \multicolumn{2}{|c|}{ Ametryn + Assist (jato no $3^{\circ}$ par, 12 folhas) } & $9,28 \mathrm{ab}$ & $9,38 \mathrm{ab}$ \\
\hline \multicolumn{2}{|c|}{ Paraquat + Extravon (jato no $1^{o}$ par, 12 folhas) } & $9,20 \mathrm{ab}$ & $9,65 \mathrm{ab}$ \\
\hline \multicolumn{2}{|l|}{ Testemunha com capina } & $8,80 \mathrm{ab}$ & $9,53 \mathrm{ab}$ \\
\hline \multicolumn{2}{|c|}{ Cyanazine + Simazine ( 4 folhas $)$} & $8,73 \mathrm{ab}$ & $9,20 \mathrm{abc}$ \\
\hline \multicolumn{2}{|c|}{ Paraquat + Extravon (jato no $3^{\underline{o}}$ par, 12 folhas) } & $8,70 \mathrm{ab}$ & $9,15 \mathrm{abc}$ \\
\hline \multicolumn{2}{|c|}{ Retirada de folhas ( $1^{\circ}$ par, 12 folhas $)$} & $8,58 \mathrm{ab}$ & $9,68 \mathrm{ab}$ \\
\hline \multicolumn{2}{|l|}{ Testemunha sem capina } & $7,95 \mathrm{ab}$ & $7,90 \mathrm{c}$ \\
\hline \multicolumn{2}{|c|}{ Cyanazine + Simazine + Assist $(6$ folhas $)$} & $7,80 \mathrm{ab}$ & $8,98 \mathrm{abc}$ \\
\hline \multicolumn{2}{|l|}{ Cyanazine + Simazine $(6$ folhas $)$} & $7,58 \mathrm{~b}$ & $8,43 \mathrm{bc}$ \\
\hline \multicolumn{2}{|c|}{ Cyanazine + Simazine + Assist (4 folhas) } & -- & $10,10 \mathrm{a}$ \\
\hline 1994/95 - Média Geral = 8,70 & $\mathrm{CV}=8,56 \%$ & Valor de $\mathrm{F}=3,34 * *$ & $\mathrm{DMS}=1,83$ \\
\hline 1995/96 - Média geral $=9,23$ & $\mathrm{CV}=6,85 \%$ & Valor de $\mathrm{F}=3,49 *$ & $\mathrm{DMS}=1,57$ \\
\hline
\end{tabular}

${ }^{1}$ Médias seguidas pela mesma letra não diferem entre si, a $5 \%$ de probabilidade, pelo teste de Tukey. 
Tabela 3 - Número de plantas (estande) de sorgo para os diferentes tratamentos estudados, nos anos agrícolas 1994/95 e 1995/96. Embrapa Milho e Sorgo, Sete Lagoas-MG

\begin{tabular}{|c|c|c|c|}
\hline \multirow{2}{*}{\multicolumn{2}{|c|}{ Tratamentos }} & \multicolumn{2}{|c|}{ Ano Agrícola } \\
\hline & & $1994 / 95$ & 1995/96 \\
\hline \multicolumn{2}{|l|}{ Cyanazine + Simazine ( 6 folhas $)$} & $200^{1} \mathrm{a}$ & $138 \mathrm{a}$ \\
\hline \multicolumn{2}{|c|}{ Cyazine + Simazine + Assist ( 6 folhas $)$} & $174 \mathrm{ab}$ & $144 \mathrm{a}$ \\
\hline \multicolumn{2}{|l|}{ Testemunha com capina } & $169 \mathrm{bc}$ & 148 a \\
\hline \multicolumn{2}{|c|}{ Retirada de folhas ( $1^{\circ}$ par, 12 folhas $)$} & $159 \mathrm{bc}$ & $151 \mathrm{a}$ \\
\hline \multicolumn{2}{|l|}{ Testemunha sem capina } & $158 \mathrm{bc}$ & $77 \mathrm{bc}$ \\
\hline \multicolumn{2}{|c|}{ Ametryn + Assist (jato no $1^{\circ}$ par, 12 folhas) } & $157 \mathrm{bc}$ & $150 \mathrm{a}$ \\
\hline \multicolumn{2}{|c|}{ Paraquat + Extravon (jato no $1^{\circ}$ par, 12 folhas) } & $153 \mathrm{bc}$ & $154 \mathrm{a}$ \\
\hline \multicolumn{2}{|c|}{ Ametryn + Assist (jato no $3^{\circ}$ par, 12 folhas) } & $153 \mathrm{bc}$ & $154 \mathrm{a}$ \\
\hline \multicolumn{2}{|c|}{ Retirada de folhas ( $1^{\circ}$ ao $3^{\circ}$ par, 12 folhas) } & $151 \mathrm{bc}$ & $153 \mathrm{a}$ \\
\hline \multicolumn{2}{|c|}{ Paraquat + Extravon (jato no $3^{\circ}$ par, 12 folhas) } & $145 \mathrm{c}$ & $133 \mathrm{ab}$ \\
\hline \multicolumn{2}{|l|}{ Cyanazine + Simazine ( 4 folhas $)$} & $115 \mathrm{~d}$ & $118 \mathrm{abc}$ \\
\hline \multicolumn{2}{|c|}{ Cyazine + Simazine + Assist ( 4 folhas) } & -- & $66 \mathrm{c}$ \\
\hline 1994/95 - Média geral $=158$ & $\mathrm{CV}=7,37 \%$ & Valor de $\mathrm{F}=12,84 * *$ & $\mathrm{DMS}=28,57$ \\
\hline 1995/96 - Média geral $=132$ & $\mathrm{CV}=17,34 \%$ & Valor de $\mathrm{F}=6,99 * *$ & DMS $=56,89$ \\
\hline
\end{tabular}

${ }^{1}$ Médias seguidas pela mesma letra não diferem entre si, a 5\% de probabilidade, pelo teste de Tukey.

Tabela 4 - Peso de panículas ( $\mathrm{kg} \mathrm{ha}^{-1}$, umidade dos grãos de 13\%) de plantas de sorgo para os diferentes tratamentos estudados, nos anos agrícolas 1994/95 e 1995/96. Embrapa Milho e Sorgo, Sete Lagoas-MG

\begin{tabular}{|c|c|c|c|}
\hline \multirow{2}{*}{\multicolumn{2}{|c|}{ Tratamentos }} & \multicolumn{2}{|c|}{ Ano Agrícola } \\
\hline & & $1994 / 95$ & $1995 / 96$ \\
\hline \multicolumn{2}{|c|}{ Paraquat + Extravon (jato no $1^{\circ}$ par 12 folhas) } & $5.876^{1} \mathrm{a}$ & $8.357 \mathrm{a}$ \\
\hline \multicolumn{2}{|c|}{ Ametryn + Assist (jato no $1^{\circ}$ par 12 folhas) } & $5.842 \mathrm{a}$ & $8.001 \mathrm{a}$ \\
\hline \multicolumn{2}{|c|}{ Retirada de folhas ( $1^{\circ}$ ao $3^{\circ}$ par, 12 folha $)$} & $5.770 \mathrm{a}$ & $7.938 \mathrm{a}$ \\
\hline \multicolumn{2}{|c|}{ Cyanazine + Simazine + Assist (6 folhas) } & $5.652 \mathrm{ab}$ & $7.402 \mathrm{a}$ \\
\hline \multicolumn{2}{|l|}{ Testemunha com capina } & $5.645 \mathrm{ab}$ & $8.085 \mathrm{a}$ \\
\hline \multicolumn{2}{|c|}{ Ametryn + Assist (jato no $3^{\circ}$ par, 12 folhas) } & $5.475 \mathrm{ab}$ & $8.301 \mathrm{a}$ \\
\hline \multicolumn{2}{|c|}{ Retirada de folhas ( $1^{\circ}$ par, 12 folhas) } & $5.425 \mathrm{ab}$ & $8.080 \mathrm{a}$ \\
\hline \multicolumn{2}{|l|}{ Cyanazine + Simazine ( 6 folhas $)$} & $5.331 \mathrm{ab}$ & $6.971 \mathrm{a}$ \\
\hline \multicolumn{2}{|c|}{ Paraquat + Extravon (jato no $3^{\circ}$ par, 12 folhas) } & $5.039 \mathrm{ab}$ & $6.616 \mathrm{ab}$ \\
\hline \multicolumn{2}{|l|}{ Cyanazine + Simazine (4 folhas) } & $4.172 \mathrm{bc}$ & $7.203 \mathrm{a}$ \\
\hline \multicolumn{2}{|l|}{ Testemunha sem capina } & $3.297 \mathrm{c}$ & $2.924 \mathrm{~b}$ \\
\hline \multicolumn{2}{|c|}{ Cyanazine + Simazine + Assist (4 folhas) } & -- & $4.556 \mathrm{abc}$ \\
\hline 1994/95 - Média geral = 5.229 & $\mathrm{CV}=11,58 \%$ & Valor de $\mathrm{F}=7,01 * *$ & $\mathrm{DMS}=1.490$ \\
\hline 1995/96 - Média geral = 7.036 & $\mathrm{CV}=22,08 \%$ & Valor de $\mathrm{F}=4,62 * *$ & $\mathrm{DMS}=3.860$ \\
\hline
\end{tabular}

${ }^{1}$ Médias seguidas pela mesma letra não diferem entre si, a 5\% de probabilidade, pelo teste de Tukey. 
Tabela 5 - Produção de grãos ( $\mathrm{kg} \mathrm{ha}^{-1}$, umidade dos grãos de 13\%) para os diferentes tratamentos estudados, nos anos agrícolas 1994/95 e 1995/96. Embrapa Milho e Sorgo, Sete Lagoas-MG

\begin{tabular}{|c|c|c|c|}
\hline \multirow{2}{*}{\multicolumn{2}{|c|}{ Tratamentos }} & \multicolumn{2}{|c|}{ Ano Agrícola } \\
\hline & & $1994 / 95$ & 1995/96 \\
\hline \multicolumn{2}{|c|}{ Ametryn + Assist (jato no $1^{\circ}$ par 12 folhas) } & $3094^{1}$ a & $5718 \mathrm{a}$ \\
\hline \multicolumn{2}{|c|}{ Paraquat + Extravon (jato no $1^{\circ}$ par, 12 folhas) } & $3080 \mathrm{a}$ & $6044 \mathrm{a}$ \\
\hline \multicolumn{2}{|c|}{ Retirada de folhas ( $1^{\circ}$ ao $3^{-}$par, 12 folhas) } & $3074 \mathrm{a}$ & 5736 a \\
\hline \multicolumn{2}{|c|}{ Cyanazine + Simazine + Assist (6 folhas) } & $3001 \mathrm{a}$ & $5244 \mathrm{a}$ \\
\hline \multicolumn{2}{|l|}{ Testemunha com capina } & $2974 \mathrm{a}$ & $5617 \mathrm{a}$ \\
\hline \multicolumn{2}{|c|}{ Ametryn + Assist (jato no $3^{-0}$ par, 12 folhas) } & $2857 \mathrm{ab}$ & $5556 \mathrm{a}$ \\
\hline \multicolumn{2}{|c|}{ Retirada de folhas ( $1^{\circ}$ par, 12 folhas) } & $2838 \mathrm{ab}$ & $5941 \mathrm{a}$ \\
\hline \multicolumn{2}{|l|}{ Cyanazine + Simazine (6 folhas) } & $2774 \mathrm{ab}$ & $5172 \mathrm{a}$ \\
\hline \multicolumn{2}{|c|}{ Paraquat + Extravon (jato no $3^{\circ}$ par, 12 folhas) } & $2716 \mathrm{ab}$ & $4805 \mathrm{ab}$ \\
\hline \multicolumn{2}{|l|}{ Cyanazine + Simazine ( 4 folhas) } & $2135 \mathrm{bc}$ & $5221 \mathrm{a}$ \\
\hline \multicolumn{2}{|l|}{ Testemunha sem capina } & $1669 \mathrm{c}$ & 1992 b \\
\hline \multicolumn{2}{|c|}{ Cyanazine + Simazine + Assist (4 folhas) } & -- & $3213 a b$ \\
\hline 1994/95 - Média geral $=2.747$ & $\mathrm{CV}=10,95 \%$ & Valor de $\mathrm{F}=8,89 * *$ & $\mathrm{DMS}=740$ \\
\hline 1995/96 - Média geral = 5.021 & $\mathrm{CV}=23,08 \%$ & Valor de $\mathrm{F}=4,37 * *$ & $\mathrm{DMS}=2.880$ \\
\hline
\end{tabular}

${ }^{1}$ Médias seguidas pela mesma letra não diferem entre si, a 5\% de probabilidade, pelo teste de Tukey.

No ano agrícola 1995/96, os resultados de peso de panículas e de grãos (Tabelas 4 e 5) foram semelhantes àqueles obtidos no ano anterior, e os tratamentos com desempenho inferior foram a testemunha sem capina e a aplicação de cyanazine + simazine + assist (4 folhas). Os comentários feitos para 1994/95 são válidos para esse ano agrícola.

Excetuando-se o tratamento cyanazine + simazine, principalmente com a presença de assist, aplicados no estádio de 4 folhas, o uso de herbicidas em pós-emergência na cultura do sorgo mostrou-se viável. Mesmo quando houve injúrias, estas não foram suficientes para prejudicar a produção. O bom controle das plantas daninhas proveniente do uso dos herbicidas possibilitou ao sorgo expressar melhor seu potencial produtivo.

\section{AGRADECIMENTOS}

A José Eduardo Filho, assistente de pesquisa, e a José Rubens de Oliveira, técnico agrícola da Embrapa Milho e Sorgo, pela colaboração na coleta de dados.

\section{LITERATURA CITADA}

DOGGETT, H. Physiology and agronomy. In: DOGGETT, H. Sorghum. London: Longmans, 1970. p.180-211.

KRAMER, N.W., ROSS, W.M. Cultivo de sorgo granífero en Estados Unidos. In: WALL, J.S. (Comp.) Producción y usos del sorgo. Buenos Aires: Hemisfério Sur, 1975. p.93-111.

LOOMIS, R.S., WILLIAMS, W.A. 1963. "Maximum crop productivity: an estimate”. Crop Sci., v.3, p.67, 1963.

MAGALHÃES, P.C. DURÃES, F.O.M., SILVA, J.B., KARAM, D., DUARTE, N.F., RIBEIRO, L.S. Danos causados à cultura do sorgo pela aplicação de herbicidas em pós emergência. In: CONGRESSO NACIONAL DE MILHO E SORGO, 21, 1996. Londrina. Resumos... Londrina: 1996. p.253. 
MAGAlHÃES, P.C., DURÃES, F.O.M., SILVA, J.B. Efeito da deriva de herbicidas na fonte de fotoassimilados em sorgo. In: CONGRESSO BRASILEIRO DE FISIOLOGIA VEGETAL, 6. 1997. Belém. Resumos... Belém: p.227.

MAGALHÃES, P.C., DURÃES, F.O.M., OLIVEIRA, A.C. Efeitos do quebramento do colmo no rendimento de grãos de milho. Ci. Agrotec., v.22, n.3, p.279-289, 1998.

MAGALHÃES, P.C., DURÃES, F.O.M., OLIVEIRA, A.C., GAMA, E.E.G. Efeitos de diferentes técnicas de despendoamento na produção de milho. Sci. Agríc., v.56, n.1, p.77-82, 1999.

PAUL, C.L. Aspectos fisiologicos del crescimiento y desarollo del sorgo. In: PAUL, C.L. Agronomia del sorgo. Patancheru: ICRISAT, 1990. p 4368.

PEACOCK, J.M., WILSON, G.L. Sorghum. In: GOLDSWORTHY, P., FISHER, N.M., (Eds.) The physiology of field crops. New York: John Wiley \& Sons, 1984.

RITCHIE, S., HANWAY, J. J. How a corn plant develops. Ames: Iowa State University of Science and Technology, Cooperative Extension Service, 1989.
SANTOS, F.G., SILVA, J.B., RODRIGUES, J.A.S., KARAM,D. Tolerância de linhagens de sorgo a cloroacetamidas e dinitroanilinas. Sete Lagoas: CNPMS - EMBRAPA, 1998. p.1-8. (Pesquisa em Andamento, 22)

SILVA, J.B., PIRES, N.M. Controle de plantas daninhas na cultura do milho. Inf. Agropec., v.14, n.164, p.17-20, 1990.

SILVA, J.B., PASSINI, T., VIANA, A.C. Controle de plantas daninhas na cultura do sorgo. In: Empresa Brasileira de Pesquisa Agropecuária Embrapa. Centro Nacional de Pesquisa Milho e Sorgo (Sete Lagoas, MG). Recomendações para o cultivo do sorgo. Sete Lagoas, 1998. p.4144 (EMBRAPA - CNPMS. Circular Técnica, 1).

SORGO: em grão - $1^{\text {a }}$ safra. Levantamento sistemático da produção agrícola, v.6, n.4, p.43, 1998.

STEEL, R.G.D., TORRIE, J.H. Principles and procedures of statistics. New York:: McGrawHill, 1980. 481p.

STOSKOPF, N.C. Cereal grain crops. New York: Peston Publ. Co., 1985.

WEED SCIENCE SOCIETY OF AMERICA. Herbicide handbook. 7.ed. Champaign: WSSA, Champaign, 1994. 352p. 